\title{
Paraoxonase 1 (PON1) Q192R Gene Polymorphism and Cancer Risk: A Meta-Analysis Based on 30 Publications
}

\author{
Meng Zhang ${ }^{1,4 \&}$, Hu Xiong ${ }^{2 \&}$, Lu Fang ${ }^{3 \&}$, Wei Lu ${ }^{1,4}$, Xun Wu ${ }^{6}$, Zhan-Sen Huang ${ }^{5}$, \\ Yong-Qiang Wang ${ }^{1,4}$, Zhi-Ming Cai ${ }^{1 *}$, Song $\mathrm{Wu}^{1,5 *}$
}

\begin{abstract}
Common genetic variation Q192R in the paraoxonase $1(P O N 1)$ gene has been considered to be implicated in the development of many cancers. Nevertheless, results from the related studies were inconsistent. To elucidate the association, we performed a meta-analysis for 8,112 cases and 10,037 controls from 32 published case-control studies. Odds ratios (ORs) with $95 \%$ confidence intervals (CIs) were used to assess the strength of the association by STATA 12.0 software. Overall, we revealed that the $P O N I-192 \mathrm{R}$ allele was associated with a reduced risk of the overall cancers. Moreover, in the stratified analysis by cancer types (breast cancer, prostate cancer, brain cancer etc.), the results showed that $P O N 1-192 \mathbf{R}$ allele was associated with a decreased risk in breast cancer ( $\mathbf{R} v s \mathbf{Q}$ :

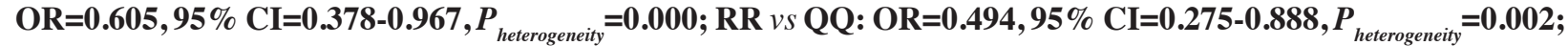
RQ vs QQ: $\mathrm{OR}=\mathbf{0 . 4 6 5 , 9 5 \%} \mathrm{CI}=\mathbf{0 . 2 5 9 - 0 . 8 3 5}, \boldsymbol{P}_{\text {heterogeneity }}=\mathbf{0 . 0 0 0}$; and RR+RQ vs QQ: $\mathrm{OR}=0.485,95 \% \mathrm{CI}=0.274-0.857$, $\left.P_{\text {heterogeneity }}=\mathbf{0 . 0 0 0}\right)$, and associated with prostate cancer in homozygote (RR vs QQ: $\mathrm{OR}=\mathbf{0 . 4 7 5}, 95 \% \mathrm{CI}=\mathbf{0 . 2 5 1 -}$

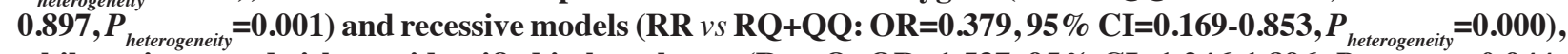
while an increased risk was identified in lymphoma $\left(R\right.$ vs $Q: O R=1.537,95 \% C I=1.246-1.896, P_{\text {heterogeneity }}=0.944$; RR vs QQ: OR=2.987, 95\% CI=1.861-4.795, $P_{\text {heterogeneity }}=0.350 ; \mathbf{R R}+\mathrm{RQ}$ vs $\mathrm{QQ}: \mathrm{OR}=1.354,95 \%$ CI=1.021-1.796, $P_{\text {heterogeneity }}=0.824$; and $\mathrm{RR}$ vs $\mathrm{RQ}+\mathrm{QQ}: \mathrm{OR}=\mathbf{2 . 9 3 4 , 9 5 \%} \mathrm{CI}=1.869-4.605, P_{\text {heterogeneit }}=0.433$ ), and an increased risk in prostate cancer under heterozygote comparison (RQ vs $Q Q: O R=1.782,95 \%$ CI $\left.=1.077-2.950, P_{\text {heterogeneity }}=0.000\right)$

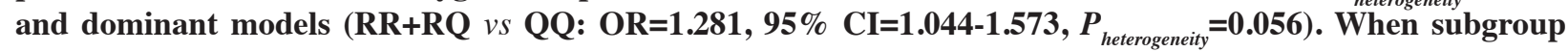
analysis that performed by the control source (hospital based or population based), a decreased risk of the overall cancers was revealed by homozygote $\left(R R\right.$ $\left.s ~ Q Q: ~ O R=0.601,95 \% C I=0.366-0.987, P_{\text {heterogeneity }}=0.000\right)$ and dominant

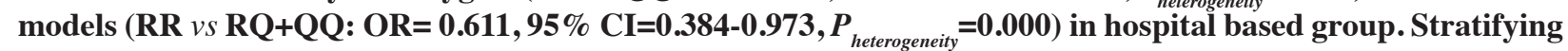
by ethnicity, a significantly reduced risk of the overall cancers under allele contrast model $(R$ vs $Q: 0 R=0.788$, 95\% CI $=\mathbf{0 . 6 2 6 - 0 . 9 9 3 ,}, P_{\text {hetergenenty }}=\mathbf{0 . 0 0 0}$ ) was uncovered in Caucasian. In summary, these findings suggested that PONI Q192R polymorphism was associated with a reduced risk of the overall cancers, nevertheless, it might increase cancer susceptibility of prostate and lymphoma risk. Large well-designed epidemiological studies will be continued on this issue of interest.
\end{abstract}

Keywords: Paraoxonase 1 - Q192R - polymorphism - cancer - meta-analysis

Asian Pac J Cancer Prev, 16 (10), 4457-4463

\section{Introduction}

About 14.1 million cancer cases and 8.2 million cancer deaths were reported in the GLOBOCAN 2012, indicating that cancer has already been a critical public health problem around the world (Torre et al., 2015). It is known to us that cancer is a disorder arising from complex interactions between genetic predispositions and environmental factors (Pharoah et al., 2004; Bredberg, 2011). And gene PON1 is located on the long arm of the chromosome 7q21.3 (Humbert et al., 1993), and the protein encoded by this gene is responsible for the hydrolysing organophosphate pesticides and nerve gasses process. Studies indicated that the activity of $P O N 1$ can be influenced by the polymorphisms of the PON1. Besides, several variants in PON1, such as Q192R, L55M etc., have been uncovered as biologically plausible candidates for effects on cancer. The first polymorphism (rs662A $>G$ ) was arising from the substitution of glutamine $(\mathrm{Q}$ genotype) by arginine (R genotype) at position 192 in exon 6 of the PON1 genes. Previous studies suggested that the PON1 activity of the PON1 192R allele carriers was identified to be higher than that of the $\mathrm{Q}$ carriers (Davies et al., 1996; Mackness et al., 1997; Li et al., 
2000). Recently, several studies have uncovered the association between Q192R polymorphism and malignant tumor susceptibility, including bladder cancer (Ozturk et al., 2009), renal cancer (Uyar et al., 2011) and glioma (Zhao et al., 2012). In the study conducted by Aygac et al. (2009), they investigated the association between PON1 Q192R polymorphism and ovarian cancer risk in a small sized case-control study of 51 cases and 54 controls in a Turkish Population, and revealed that this polymorphism increased the risk of ovarian cancer. Nevertheless, a lack of association between this polymorphism and brain astrocytoma or meningioma risk was also obtained by Martinez et al. (2010).

Based on the significant role of PON1 in cancer carcinogenesis and the genotype-phenotype correlation, we hypothesized that genetic variant Q192R in PON1 might be associated with cancer susceptibility. Awkward, the data reported are conflicting and inconclusive. Thus, we conducted a meta-analysis aiming to define the association between the Q192R polymorphism and cancer risk.

\section{Materials and Methods}

\section{Search strategy}

We searched the PubMed, Web of Science, Google Scholar and Embase for all relevant articles before March 22,2015 , by using the keywords "paraoxonase 1" or "PON1," "polymorphism," "tumor," or "malignancy," or "cancer," or "carcinoma". Additional reports on this issue were uncovered by conducting a hand search of the references extracting from the reviews or original research articles. All the retrieved results were confined to human populations and the genotype frequency can be obtained from these reports. When different authors published more than one of the same population or the same authors reported the overlapping data, we will select the most recent or comprehensive study into our metaanalysis. Besides, when one publication reported more than one cancer types or populations, we will extract the data separately.

\section{Inclusion criteria and exclusion criteria}

Reports were enrolled in our study keeping to the following criteria: $i$ ) Reports that assessed the association between the Q192R polymorphisms in PON1 and cancer risk; ii) Reports that designed in case-control study; iii) The genotype frequency was available for the cases and controls, or we can get it through calculating. Reports were removed from our report when they were: $i$ ) Case-only study, review or case report; ii) Reports without efficient genotype frequency data; iii) Overlapping reports; $i v$ ) Reports related to Animals.

\section{Data extraction}

Three of the authors (Meng Zhang, Hu Xiong and Lu Fang) extracted the detailed data from these eligible reports independently. Consensus for any controversy was reached and all the case-control studies followed the inclusion criteria. For each report, the following data will be gathered: the last name of the first author, the publication year, the ethnicity of each population, the genotype frequency for the cases and controls, the control source, the genotyping methods and cancer types. The ethnic descents can be divided into Caucasian, Asian, African or Mixed ethnicity group (more than one ethnic descent).

\section{Statistical analysis}

We used the OR and 95\% CI to estimate the strength of the associations between Q192R polymorphism in PON1 and the cancer risk under five genetic models: allele contrast (R vs $\mathrm{Q})$, homozygote (RR vs $\mathrm{QQ})$, heterozygote comparison (RQ vs QQ), recessive (RR vs $\mathrm{RQ} / \mathrm{QQ})$, and dominant (RR/RQ vs QQ) models. We also performed stratified analysis by ethnicity and the type of cancers. Nevertheless, when only one cancer type encompassed less than two case-control studies, we will subdivide it into the group of "Other Cancers". Besides, we calculated the heterogeneity via a chi-square based $\mathrm{Q}$ statistic test. By calculating $\mathrm{I}^{2}$ and $P$ values, the effect of heterogeneity can be quantified. Once the $\mathrm{I}^{2}$ value $<50 \%$ and $P>0.10$, suggesting that no significant heterogeneity was uncovered, and ORs can be pooled by a fixed-effects model. If not, we will select a random-effects model (DerSimonian and Laird, 1986). In addition, a professional web-based program can be used to tested the HardyWeinberg equilibrium (HWE) (http://ihg2.helmholtzmuenchen.de/cgibin/hw/hwa1.pl) for the control group (Zamora-Ros et al., 2013); if $P>0.05$, suggesting that the control group accords with the HWE balance. We further performed sensitivity analysis to evaluate the stability of these data.

When HWE disequilibrium existed, we will apply sensitivity analysis to evaluate the stability of these data by removing a single study from the enrolled publications to uncover the impression of the separate data set on the pooled ORs $(P<0.05$ was considered statistically significant) (Tobias and Campbell, 1999).Finally, possibility of the publication bias was investigated by using Begg's test and Egger's test(Begg and Mazumdar, 1994; Egger et al., 1997), and $P<0.05$ was considered as statistically significant. All the statistical tests can be conducted by STATA Software (version 12.0, stata Corp), and $P<0.05$ for any tests or genetic models were regarded as statistically significant.

\section{Results}

\section{Publication characteristics}

After elaborated examination according to the inclusion criteria, a total of 30 publications enrolled in our meta-analysis comprising 8,112 cases and 10,037 controls (Kerridge et al., 2002; Lincz et al., 2004; Antognelli et al., 2005; Lee et al., 2005; Searles Nielsen et al., 2005; Van Der Logt et al., 2005; Kafadar et al., 2006; Gallicchio et al., 2007; Lurie et al., 2008; Rajaraman et al., 2008; Stevens et al., 2008; Antognelli et al., 2009; Arpaci et al., 2009; Ozturk et al., 2009; Martinez et al., 2010; Naidu et al., 2010; Aksoy-Sagirli et al., 2011; Ergen et al., 2011; Hussein et al., 2011; Uyar et al., 2011; de Aguiar Goncalves et al., 2012; Vecka et al., 2012; Wang et al., 
2012; Akkiz et al., 2013; Antognelli et al., 2013; ConesaZamora et al., 2013; Kokouva et al., 2013; Vasconcelos et al., 2014; Ahmed et al., 2015; Eom et al., 2015) (Table 1). For PON1 Q192R polymorphism, all 32 case-control studies deriving from 30 publications reported the available data, including 6 breast cancer studies, 4 brain tumors, 3 prostate cancer, 2 ovarian cancer, 2 lymphoma, 4 lung cancer, and 2 colorectal cancer studies and the others (9 studies, including Osteosarcoma, Multiple Myeloma, Hepatocellular Carcinoma and so on.), which were classified into the "other cancers" group. The flow chart of the study screening in summarized in Figure 1. We presented 21 studies of Caucasian descendents, 5 of Asian descendents, and 6 with mixed ethnicity.

Besides, there were 23 studies performed by PCRRFLP, while 9 studies conducted by TaqMan assay. Furthermore, most of the controls for the case group were sex- and age matched, including 17 population based and 15 hospital based. Notably, there are 9 case-control studies deviated from the HWE (Table 1) (Antognelli et al., 2005; Lee et al., 2005; Rajaraman et al., 2008; Stevens et al., 2008; Antognelli et al., 2009; Ozturk et al., 2009; Vecka et al., 2012; Antognelli et al., 2013; Conesa-Zamora et al., 2013).

\section{Meta-analysis}

To sum up, our results have revealed that the PON1192R allele was associated with a reduced risk of the overall cancers in allele contrast model $(\mathrm{R} v s \mathrm{Q}: \mathrm{OR}=$ $\left.0.843,95 \% \mathrm{CI}=0.725-0.979, P_{\text {heterogeneity }}=0.000\right)$ (Table 2 , Figure 2a). In the cancer type subgroup analysis, we identified an increased risk in lymphoma ( $\mathrm{R}$ vs $\mathrm{Q}$ : $\mathrm{OR}=1.537,95 \% \mathrm{CI}=1.246-1.896, P_{\text {heterogeneity }}=0.944 ; \mathrm{RR}$

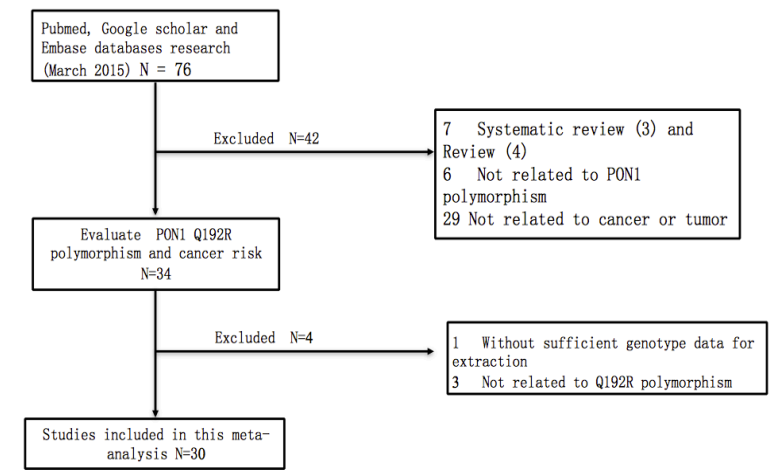

Figure 1. Flow Chart Showing the Study Selection Process. Finally, 30 publications were retrieved reporting a total of 8,112 cases and 10,037 controls

Table 1. Characteristics of Eligible Case-control Studies Included in the Meta-analysis

\begin{tabular}{|c|c|c|c|c|c|c|c|c|c|c|c|c|c|c|}
\hline First $A$ & ear & Etihnicity & & & & & Case & & & Contro & & & & \\
\hline & & & & & & QQ & & $\mathrm{RR}$ & QQ & $\mathrm{QR}$ & $\mathrm{RR}$ & HWE & $P$ & 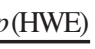 \\
\hline ee e & 2005 & Asian & TaqMan & P-B & Lung Cancer & 24 & 80 & 73 & 11 & 89 & 77 & 5 & 0.025 & $\mathrm{~N}$ \\
\hline W & 12 & & $\mathrm{P}$ & & Lung & 36 & 177 & 143 & 38 & 84 & 62 & & & \\
\hline Ahmec & 2015 & Asian & CR-RF & P-B & Colorectal Cancer & 30 & 16 & 4 & 20 & 36 & 24 & 76 & .38 & $\mathrm{Y}$ \\
\hline Akkiz et al. & 2013 & Caucasian & PCR-RFLP & P-B & $\begin{array}{l}\text { ellular } 1 \\
\text { na }\end{array}$ & 109 & 95 & 13 & 115 & 88 & 14 & & 0.6 & $\mathrm{Y}$ \\
\hline Naidı & 10 & & PCR-RFLP & & & 200 & 158 & 29 & 115 & 115 & 22 & 0.81 & 0.37 & Y \\
\hline & 13 & & $\mathrm{CR}$ & & & 291 & 250 & 30 & 707 & 258 & 203 & 244.08 & $3<0.01$ & \\
\hline & 2015 & Asi & PCR-1 & & & 37 & 170 & 209 & 48 & 188 & 180 & 11 & 0.92 & $\mathrm{Y}$ \\
\hline Uyar & 2011 & Caucasian & PCR-RFLP & P-B & & 38 & 21 & 1 & 27 & 27 & 6 & 0.039 & 0.84 & $\mathrm{Y}$ \\
\hline $\begin{array}{l}\text { de A } \\
\text { Gon }\end{array}$ & 2012 & Mixed & TaqMan & H-B & Acute Leukemia & 96 & 102 & 40 & 74 & 106 & 54 & 1.79 & 0.18 & $\mathrm{Y}$ \\
\hline t al. & 2011 & & PCR-RFLP & & & 93 & 111 & 19 & 121 & 93 & 20 & & 0.72 & $\mathrm{Y}$ \\
\hline & 2010 & & PCR- & & & 27 & 21 & 2 & 15 & 33 & 2 & & & $\mathrm{Y}$ \\
\hline & 2006 & & PCR- & & & 259 & 182 & 42 & 238 & 198 & 47 & & & $\mathrm{Y}$ \\
\hline & 2006 & & PCR- & & & 17 & 4 & 12 & 6 & 29 & 17 & & & $\mathrm{Y}$ \\
\hline & 2007 & & PCR & & & 38 & 15 & 5 & 469 & 353 & 82 & & 19 & $\mathrm{Y}$ \\
\hline & 2009 & & PCR- & & & 484 & 50 & 13 & 340 & 152 & 52 & .19 & $<0.01$ & $\mathrm{~N}$ \\
\hline & 2011 & & PCR- & & & 51 & 41 & 8 & 46 & 42 & 12 & & & $\mathrm{Y}$ \\
\hline Veck & 2012 & & PCR- & & Cancer & 40 & 28 & 5 & 40 & 20 & 13 & 9.7 & 018 & $\mathrm{~N}$ \\
\hline & 1.2013 & isian & Taq & & & 83 & 99 & 33 & 100 & 104 & 10 & & & $\mathrm{~N}$ \\
\hline & 2014 & & $\mathrm{Taq}$ & & Imor & 36 & 85 & 41 & 104 & 160 & 72 & & & $\mathrm{Y}$ \\
\hline Kokouva et al. & 2012 & Caucasian & PCR-RFLP & H-B & $\begin{array}{l}\text { Lym } \\
\text { poiet }\end{array}$ & 13 & 88 & 15 & 181 & 141 & 29 & 0.044 & 0.83 & Y \\
\hline & 10 & & & & & 31 & 33 & 9 & 22 & 89 & 109 & & & $\mathrm{Y}$ \\
\hline & 2009 & & & & & 8 & 53 & 15 & 37 & 84 & 14 & & & \\
\hline & 2002 & & PCR- & & & 73 & 50 & 39 & 103 & 74 & 22 & & 3 & $\mathrm{Y}$ \\
\hline i et al. & 2005 & casian & PCR & & & 197 & 168 & 20 & 212 & 85 & 64 & & $<0.01$ & \\
\hline & 2008 & & TaqM & & & 66 & 120 & 86 & 122 & 211 & 111 & & & \\
\hline & 2009 & Caucasian & PCR-RFLP & $\mathrm{H}-\mathrm{B}$ & Ovar & 38 & 6 & 6 & 17 & 29 & 6 & & 3 & \\
\hline & 2005 & Caucasian & PCR-RFLP & $\mathrm{P}-$ & ctal Cancer 1 & 180 & 150 & 24 & 158 & 120 & 17 & & & \\
\hline & 2008 & Mixed & TaqMan & $\mathrm{H}-$ & & 266 & 207 & 39 & 244 & 165 & 44 & 4. & & $\mathrm{~N}$ \\
\hline Stevens et al. & 2008 & Mixed & TaqMan & $\mathrm{P}-1$ & & 624 & 537 & 95 & 656 & 487 & 121 & & 029 & $\mathrm{~N}$ \\
\hline Searles Nielsen et al. & 1.2005 & Mixed & TaqMan & P-B & Brain Tumor & 32 & 28 & 6 & 100 & 105 & 31 & 0.17 & 0.68 & $\mathrm{Y}$ \\
\hline Lincz et al. & 2004 & Caucasian & PCR-RFLP & P-B & Multiple Myeloma & a 33 & 41 & 16 & 103 & 74 & 22 & 2.35 & 0.13 & Y \\
\hline Kafadar et al. & 2006 & Caucasian & PCR-RFLP & $\mathrm{H}-\mathrm{B}$ & Brain Tumor & 43 & 26 & 15 & 24 & 18 & 8 & 1.96 & 0.16 & $\mathrm{Y}$ \\
\hline
\end{tabular}

*PCR-RFLP: polymerase chain reaction-restriction fragment length polymorphism; HWE: Hardy-Weinberg equilibrium; Y: polymorphisms conformed to HWE in the control group; N: polymorphisms didn`t conform to HWE in the control group. H-B: hospital based; P-B: population based 
vs QQ: $\mathrm{OR}=2.987,95 \% \mathrm{CI}=1.861-$ 4.795, $P_{\text {heterogeneity }}=0.350 ; \mathrm{RR}+\mathrm{RQ} v s$ QQ: $\mathrm{OR}=1.354,95 \% \mathrm{CI}=1.021-1.796$, $P_{\text {heterogeneity }}=0.824$; and RR $v s \mathrm{RQ}+\mathrm{QQ}$ : $\mathrm{OR}=2.934,95 \% \mathrm{CI}=1.869-4.605$, $\left.P_{\text {heterogeneity }}=0.433\right)$ and prostate cancer under heterozygote comparison (RQ vs $\mathrm{QQ}: \mathrm{OR}=1.782,95 \% \mathrm{CI}=1.077$ $\left.2.950, P_{\text {heterogeneity }}=0.000\right)$ and dominant models (RR+RQ vs QQ: $\mathrm{OR}=1.281,95 \% \mathrm{CI}=1.044-1.573$, $\left.P_{\text {heterogeneity }}=0.056\right)$. Nevertheless, a decreased risk was identified in breast cancer $(\mathrm{R}$ vs $\mathrm{Q}: \mathrm{OR}=0.605,95 \%$ $\mathrm{CI}=0.378-0.967, P_{\text {heterogeneity }}=0.000$; RR vs QQ: OR=0.494,95\% CI=0.275$0.888, P_{\text {heterogeneity }}=0.002 ; \mathrm{RQ} v s \mathrm{QQ}$ : $\mathrm{OR}=0.465,95 \% \mathrm{CI}=0.259-0.835$, $P_{\text {heterogeneity }}=0.000$; and $\mathrm{RR}+\mathrm{RQ} v s$ QQ: OR $=0.485,95 \% \mathrm{CI}=0.274$ $\left.0.857, P_{\text {heterogeneity }}=0.000\right)$, and prostate cancer in homozygote and recessive models (RR vs QQ: OR $=0.475,95 \%$ $\mathrm{CI}=0.251-0.897, P_{\text {heterogeneity }}=0.001$ and RR vs RQ+QQ: $\mathrm{OR}=0.379,95 \%$ $\mathrm{CI}=0.169-0.853, P_{\text {heterogeneity }}=0.000$ ).

Furthermore, when subgroup analysis that performed by the control source (hospital based or population based), a decreased risk of the overall cancers was observed in homozygote (RR vs QQ: OR $=0.601,95 \%$ $\left.\mathrm{CI}=0.366-0.987, P_{\text {heterogeneity }}=0.000\right)$ and dominant models (RR vs RQ+QQ: $\mathrm{OR}=0.611,95 \% \mathrm{CI}=0.384-0.973$, $\left.P_{\text {heterogeneity }}=0.000\right)$ in the hospital based group. Similarly, when stratified by ethnicity, a significantly decreased risks of cancers in Caucasian population (but not Asian) for comparison of $\mathrm{R} v s \mathrm{Q}$ $(\mathrm{OR}=0.788,95 \% \mathrm{CI}=0.626-0.993$, $P_{\text {heterogeneity }}=0.000$, Figure $2 \mathrm{~b}$ ) was uncovered.

Publication bias and sensitivity analysis

Here, we conducted a sensitivity analysis to investigate the impression of individual publications on the integrated data by removing a single report from the pooled analysis each time. And no individual study was revealed influenced the pooled OR (Figure 3). Publication bias was assessed by Egger's test and Begg's funnel plot. No apparent publication bias was uncovered by these tests in PON1 Q192R polymorphisms (PON1 Q192R: R vs Q: Begg's test: $\mathrm{z}=2.22$ $P=0.026$; Egger's test: $\mathrm{t}=-1.75 P=$ 0.090). 
A)

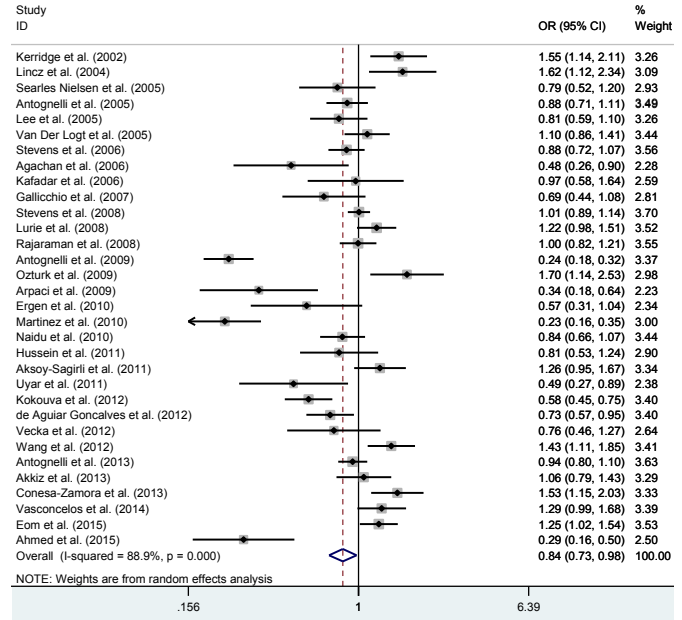

B)

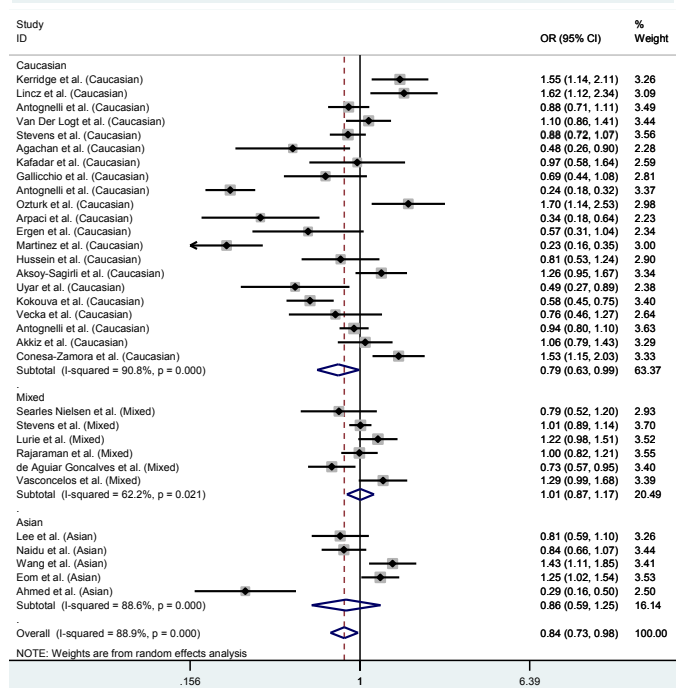

Figure 2. A) Meta-analysis of the Association between PON1 Q192R Polymorphism and Overall Cancer Risk ( $\mathbf{R} v s$ Q); B) Subgroup Analysis of the Association between PON1 Q192R Polymorphism and Cancer Risk by Ethnicity (R vs Q)

\section{Discussion}

Previous studies suggested that an increased risk of a variety of cancers may relate to oxidative stress and free radicals (Ames, 1983; Sun, 1990). Plenty of endogenous free-radical scavenging systems were existed in our body. $P O N 1$, an antioxidant enzyme, may lead to the imbalance of the antioxidant/oxidant system (Karaman et al., 2010), and induce oxidative stress and the ROS formation. Previous studies have revealed a depressed expression of PON1 in lung cancer (Elkiran et al., 2007), pancreatic(Akcay et al., 2003a), and gastric cancer(Akcay et al., 2003b). Furthermore, publications also showed that Q192R polymorphism increased the risk of bladder cancer(Ozturk et al., 2009) and renal cancer(Uyar et al., 2011), while a lack of association between this polymorphism and brain tumor, colorectal cancer risk was also uncovered(Van Der Logt et al., 2005; Rajaraman et al., 2008). R allele may contribute to the improvement of the detoxification activity of $P O N 1$ enzyme confront with latently carcinogenic products of oxidative stress and lipid peroxidation (Cejas et al., 2004).

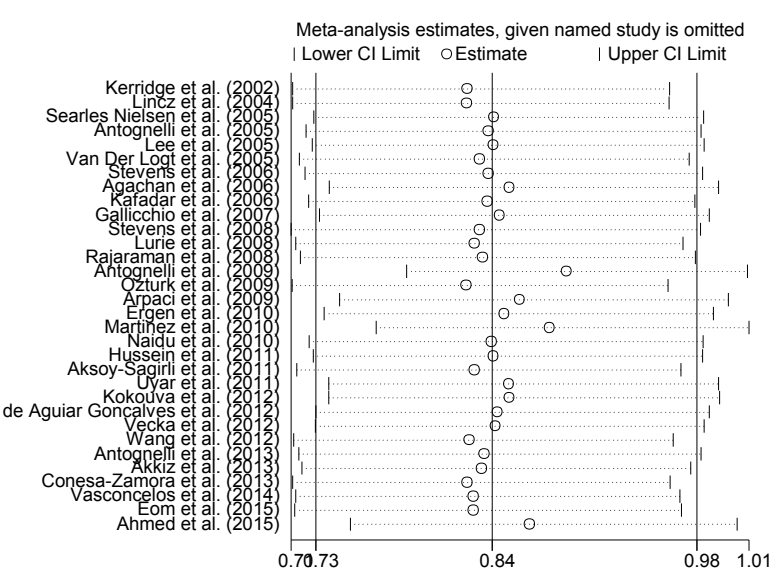

Figure 3. Sensitivity Analysis of Overall OR CoEfficients for PON1 Q192R (R vs Q). Results were calculated by omitting each study in turn. The two ends of the dotted lines represent the $95 \%$ CI

In our work, we aim to investigate the association between PON1-Q192R polymorphism and cancer risk. We identified that $\mathrm{Q} 192 \mathrm{R}$ polymorphism was associated with a decreased risk for cancer development, particularly for breast cancer. In the study conducted by Delimaris et al.(Delimaris et al., 2007), they reported that, during the pathogenesis of breast cancer, oxidative stress may contribute to the cell proliferation and malignant conversion process. Thus, it is fair to predict that PON1, which is a part of the lipid peroxidation scavenging systems, may affect the pathogenesis of breast cancer. In the subgroup analysis by cancer type, the results showed that PON1-192R allele was associated with a decreased risk in breast cancer and prostate cancer (in homozygote and recessive models), indicating that $P O N 1-\mathrm{Q} 192 \mathrm{R}$ polymorphism may work as a protective factor for these two cancer types. Nevertheless, an increased risk was uncovered in lymphoma and prostate cancer (in heterozygote comparison and dominant models), a result consistent with previous studies (Kerridge et al., 2002; Antognelli et al., 2005). Stratifying by control source (hospital based or population based), a decreased risk of the overall cancers was revealed by homozygote and dominant models in hospital based group.

Notably, in the stratified analysis by ethnicity, a significantly reduced risk of the overall cancers under allele contrast model was uncovered in Caucasian. Previous studies indicated that PON1 192 Q allele carriers were reported to be lower than that of the $\mathrm{R}$ carriers (Davies et al., 1996; Mackness et al., 1997; Li et al., 2000), and a lower $P O N 1$ level was regarded as a risk for cancer (Ellidag et al., 2014); notably, allele distributions varied obviously in control groups when stratified by the ethnic group, a result consistent with those reported by the National Center of Biotechnology Information (NCBI) for Caucasian (Q: 0.668) and Asian population (Q: 0.430).

Although we have conducted a comprehensive retrieve for all attainable eligible publications and presented with a landscape of the association between PON1 Q192R polymorphism and cancer risk, there are still existed several limitations that should be interpreted. Firstly, the number of the publications and the sample size of 
each reports were relatively small, when a stratification analysis was performed for the cancer type, ethnicity, or the control source, resulting in insufficient capacity which cannot identify slight influence on cancers. Secondly, most of the enrolled publications were Caucasian that might result in the inconspicuousness. Thirdly, there was no data available for Africans. Fourthly, since the lack of raw data from these publications, no further assessment was performed for the potential gene-gene interactions or gene-environment interactions. In conclusion, our study has successfully elaborated that PON1-192R allele was associated with a significantly decreased risk of the overall cancers. More research will be continued in order to refine the investigation on this issue of interest, with larger sample size, detailed original data, especially investigations for African.

\section{References}

Ahmed NS, Shafik NM, Elraheem OA, et al (2015). Association of paraoxonase-1(Q192R and L55M) gene polymorphisms and activity with colorectal cancer and effect of surgical intervention. Asian Pac J Cancer Prev, 16, 803-9.

Akcay MN, Polat MF, Yilmaz I, et al (2003a). Serum paraoxonase levels in pancreatic cancer. Hepatogastroenterology, $\mathbf{5 0}$, ccxxv-ccxxvii.

Akcay MN, Yilmaz I, Polat MF, et al (2003b). Serum paraoxonase levels in gastric cancer. Hepatogastroenterology, 50, cclxxiii-cclxxv.

Akkiz H, Kuran S, Akgollu E, et al (2013). Effect of PON1 gene polymorphisms in Turkish patients with hepatocellular carcinoma. Meta Gene, 1, 93-101.

Aksoy-Sagirli P, Cakmakoglu B, Isbir T, et al (2011). Paraoxonase-1 192/55 polymorphisms and the risk of lung cancer in a Turkish population. Anticancer Res, 31, 2225-9.

Ames BN (1983). Dietary carcinogens and anticarcinogens. Oxygen radicals and degenerative diseases. Science, 221, 1256-64.

Antognelli C, Del Buono C, Ludovini V, et al (2009). CYP17, GSTP1, PON1 and GLO1 gene polymorphisms as risk factors for breast cancer: an Italian case-control study. $B M C$ Cancer, 9, 115.

Antognelli C, Mearini L, Talesa VN, et al (2005). Association of CYP17, GSTP1, and PON1 polymorphisms with the risk of prostate cancer. Prostate, 63, 240-51.

Antognelli C, Mezzasoma L, Mearini E, et al (2013). Glyoxalase $1-419 \mathrm{C}>\mathrm{A}$ variant is associated with oxidative stress: implications in prostate cancer progression. PLoS One, $\mathbf{8}$, 74014.

Arpaci A, Gormus U, Dalan B, et al (2009). Investigation of PON1 192 and PON1 55 polymorphisms in ovarian cancer patients in Turkish population. In Vivo, 23, 421-4.

Begg CB, Mazumdar M (1994). Operating characteristics of a rank correlation test for publication bias. Biometrics, 50, 1088-101.

Bredberg A (2011). Cancer: more of polygenic disease and less of multiple mutations? A quantitative viewpoint. Cancer, 117, 440-5.

Cejas P, Casado E, Belda-Iniesta C, et al (2004). Implications of oxidative stress and cell membrane lipid peroxidation in human cancer (Spain). Cancer Causes Control, 15, 707-19.

Conesa-Zamora P, Ruiz-Cosano J, Torres-Moreno D, et al (2013). Polymorphisms in xenobiotic metabolizing genes (EPHX1, NQO1 and PON1) in lymphoma susceptibility: a case control study. BMC Cancer, 13, 228.
Davies HG, Richter RJ, Keifer M, et al (1996). The effect of the human serum paraoxonase polymorphism is reversed with diazoxon, soman and sarin. Nat Genet, 14, 334-6.

de Aguiar Goncalves BA, Vasconcelos GM, Thuler LC, et al (2012). NQO1 rs1800566 (C609T), PON1 rs662 (Q192R), and PON1 rs854560 (L55M) polymorphisms segregate the risk of childhood acute leukemias according to age range distribution. Cancer Causes Control, 23, 1811-9.

Delimaris I, Faviou E, Antonakos G, et al (2007). Oxidized LDL, serum oxidizability and serum lipid levels in patients with breast or ovarian cancer. Clin Biochem, 40, 1129-34.

DerSimonian R, Laird N (1986). Meta-analysis in clinical trials. Control Clin Trials, 7, 177-88.

Egger M, Davey Smith G, Schneider M, et al (1997). Bias in meta-analysis detected by a simple, graphical test. $B M J$, 315, 629-34.

Elkiran ET, Mar N, Aygen B, et al (2007). Serum paraoxonase and arylesterase activities in patients with lung cancer in a Turkish population. BMC Cancer, 7, 48.

Ellidag HY, Aydin O, Eren E, et al (2014). Decreased HDLdependent paraoxonase and arylesterase enzyme activity may indicate a worse prognosis in multiple myeloma. Asian Pac J Cancer Prev, 15, 9847-51.

Eom SY, Yim DH, Lee CH, et al (2015). Interactions between paraoxonase 1 genetic polymorphisms and smoking and their effects on oxidative stress and lung cancer risk in a Korean Population. PLoS One, 10, 119100.

Ergen A, Kilicoglu O, Ozger H, et al (2011). Paraoxonase 1 192 and 55 polymorphisms in osteosarcoma. Mol Biol Rep, 38, 4181-4.

Gallicchio L, McSorley MA, Newschaffer CJ, et al (2007). Body mass, polymorphisms in obesity-related genes, and the risk of developing breast cancer among women with benign breast disease. Cancer Detect Prev, 31, 95-101.

Humbert R, Adler DA, Disteche CM, et al (1993). The molecular basis of the human serum paraoxonase activity polymorphism. Nat Genet, 3, 73-6.

Hussein YM, Gharib AF, Etewa RL, et al (2011). Association of L55M and Q192R polymorphisms in paraoxonase 1 (PONI) gene with breast cancer risk and their clinical significance. Mol Cell Biochem, 351, 117-23.

Kafadar AM, Ergen A, Zeybek U, et al (2006). Paraoxonase 192 gene polymorphism and serum paraoxonase activity in high grade gliomas and meningiomas. Cell Biochem Funct, 24, 455-60.

Karaman E, Uzun H, Papila I, et al (2010). Serum paraoxonase activity and oxidative DNA damage in patients with laryngeal squamous cell carcinoma. J Craniofac Surg, 21, 1745-9.

Kerridge I, Lincz L, Scorgie F, et al (2002). Association between xenobiotic gene polymorphisms and non-Hodgkin's lymphoma risk. Br J Haematol, 118, 477-81.

Kokouva M, Koureas M, Dardiotis E, et al (2013). Relationship between the paraoxonase 1 (PON1) M55L and Q192R polymorphisms and lymphohaematopoietic cancers in a Greek agricultural population. Toxicology, 307, 12-6.

Lee CH, Lee KY, Choe KH, et al (2005). Effects of oxidative DNA damage induced by polycyclic aromatic hydrocarbons and genetic polymorphism of the paraoxonase-1 (PON1) gene on lung cancer. J Prev Med Public Health, 38, 345-50.

Li WF, Costa LG, Richter RJ, et al (2000). Catalytic efficiency determines the in-vivo efficacy of PON1 for detoxifying organophosphorus compounds. Pharmacogenetics, 10, 767-79.

Lincz LF, Kerridge I, Scorgie FE, et al (2004). Xenobiotic gene polymorphisms and susceptibility to multiple myeloma. Haematologica, 89, 628-9. 
Lurie G, Wilkens LR, Thompson PJ, et al (2008). Genetic polymorphisms in the Paraoxonase 1 gene and risk of ovarian epithelial carcinoma. Cancer Epidemiol Biomarkers Prev, 17, 2070-7.

Mackness B, Mackness MI, Arrol S, et al (1997). Effect of the molecular polymorphisms of human paraoxonase (PONI) on the rate of hydrolysis of paraoxon. Br J Pharmacol, 122, 265-8.

Martinez C, Molina JA, Alonso-Navarro H, et al (2010). Two common nonsynonymous paraoxonase 1 (PONI) gene polymorphisms and brain astrocytoma and meningioma. BMC Neurol, 10, 71.

Naidu R, Har YC, Taib NA (2010). Genetic polymorphisms of paraoxonase 1 (PON1) gene: association between L55M or Q192R with breast cancer risk and clinico-pathological parameters. Pathol Oncol Res, [Epub ahead of print].

Ozturk O, Kagnici OF, Ozturk T, et al (2009). 192R allele of paraoxanase $1(P O N 1)$ gene as a new marker for susceptibility to bladder cancer. Anticancer Res, 29, 4041-6.

Pharoah PD, Dunning AM, Ponder BA, et al (2004). Association studies for finding cancer-susceptibility genetic variants. Nat Rev Cancer, 4, 850-60.

Rajaraman P, Hutchinson A, Rothman N, et al (2008). Oxidative response gene polymorphisms and risk of adult brain tumors. Neuro Oncol, 10, 709-15.

Searles Nielsen S, Mueller BA, De Roos AJ, et al (2005). Risk of brain tumors in children and susceptibility to organophosphorus insecticides: the potential role of paraoxonase (PON1). Environ Health Perspect, 113, 909-13.

Stevens VL, Rodriguez C, Talbot JT, et al (2008). Paraoxonase $1(P O N 1)$ polymorphisms and prostate cancer in the CPS-II nutrition cohort. Prostate, 68, 1336-40.

Sun Y (1990). Free radicals, antioxidant enzymes, and carcinogenesis. Free Radic Biol Med, 8, 583-99.

Tobias A, Campbell MJ (1999). Modelling influenza epidemics in the relation between black smoke and total mortality. A sensitivity analysis. J Epidemiol Community Health, 53, 583-4.

Torre LA, Bray F, Siegel RL, et al (2015). Global cancer statistics, 2012. CA Cancer J Clin, 65, 87-108.

Uyar OA, Kara M, Erol D, et al (2011). Investigating paraoxonase-1 gene Q192R and L55M polymorphism in patients with renal cell cancer. Genet Mol Res, 10, 133-9.

Van Der Logt EM, Janssen CH, Van Hooijdonk Z, et al (2005). No association between genetic polymorphisms in $\mathrm{NAD}(\mathrm{P})$ $\mathrm{H}$ oxidase $\mathrm{p} 22$ phox and paraoxonase 1 and colorectal cancer risk. Anticancer Res, 25, 1465-70.

Vasconcelos GM, Goncalves BA, Montalvao-de-Azevedo R, et al (2014). PON1 Q192R polymorphism (rs662) is associated with childhood embryonal tumors. Mol Biol Rep, 41, 6111-5.

Vecka M, Jachymova M, Vavrova L, et al (2012). Paraoxonase-1 $(P O N 1)$ status in pancreatic cancer: relation to clinical parameters. Folia Biol (Praha), 58, 231-7.

Wang H, Li L, Ding L, et al (2012). Association of genetic polymorphisms in the paraoxonase 1 gene with the risk and prognosis of non-small cell lung cancer in Chinese Han population. J Investig Med, 60, 592-7.

Zamora-Ros R, Rothwell JA, Scalbert A, et al (2013). Dietary intakes and food sources of phenolic acids in the European Prospective Investigation into cancer and nutrition (EPIC) study. Br J Nutr, 110, 1500-11.

Zhao P, Zhao L, Zou P, et al (2012). Genetic oxidative stress variants and glioma risk in a Chinese population: a hospitalbased case-control study. BMC Cancer, 12, 617. 